\title{
COMPROMETIMENTO CALCULATIVO E RETALIAÇÃO: VISÃO INTEGRADA DOS CONCEITOS EM UMA ORGANIZAÇÃO PÚBLICA
}

\author{
CALCULATIVE COMMITMENT AND RETALIATION: \\ AN INTEGRATED VIEW OF THE CONCEPTS \\ IN A PUBLIC ORGANIZATION
}

Recebido 13/06/2011

Aceito 21/09/2011

Letícia Gomes Maia e Antonio Virgilio Bittencourt Bastos

\section{RESUMO}

Este artigo objetivou colaborar para a revisão da multidimensionalidade do conceito de comprometimento e para o desenvolvimento da relevante temática de pesquisa sobre os desvios de comportamento no ambiente de trabalho, por meio da discussão sobre a base calculativa do comprometimento e sua relação com comportamentos de negligência como forma de reação a um estado de insatisfação. A pesquisa teve a perspectiva quantitativa e foi realizada em uma organização pública com representações em dez capitais do Brasil. A amostragem foi aleatória e estratificada, proporcional por área de atuação dentro da organização, e resultou em 519 respondentes. Os instrumentos utilizados foram a Escala de percepção e julgamento da retaliação organizacional e a Escala de comprometimento organizacional calculativo. Os resultados demonstram que os funcionários dessa organização possuem um baixo nível de comprometimento calculativo e baixa percepção de retaliação, o que indica uma relação positiva entre os dois constructos. Esses resultados corroboram outras pesquisas, que demonstram correlações positivas entre a base calculativa e comportamentos indesejáveis, de maneira oposta às outras bases do comprometimento, e, dessa forma, ratificam a sugestão de retirada da base calculativa e o tratamento desse conceito de forma separada, como entrincheiramento organizacional.

Palavras-chave: Comprometimento. Retaliação. Administração pública. 


\section{ABSTRACT}

This article aims to contribute to the revision of the multidimensionality of the concept of commitment and the development of relevant research on the subject of misbehavior in the workplace, through the discussion on the basis of calculative commitment and its relation to behavior of negligence as a reaction to a state of dissatisfaction. The research was quantitative and the prospect was held in a public organization with offices in ten cities of Brazil. The sampling was random and stratified proportional by area of operation and resulted in 519 respondents. The instruments were: Awareness and trial of Organizational Retaliation Scale and Calculative Organizational Commitment Scale. The results show that employees of this organization have a low level of calculative commitment and low perception of retaliation, which indicates a positive relationship between the two constructs. These results corroborate other studies that show positive correlations between the calculative base and undesirable behaviors, the opposite way to other bases of multidimensional commitment - affective and normative - and thus confirm the suggestion of withdrawal of calculative basis this concept, and treatment separately as organizational entrenchment.

Keywords: Commitment. Retaliation. Public administration.

\section{INTRODUÇÃO}

Os indivíduos têm expectativas, aptidões e maneiras de perceber os fatos muito diferentes entre si. Talvez por isso seja tão difícil elaborar políticas de gestão de pessoas que deixem todos os funcionários satisfeitos e empenhando o máximo de si no desenvolvimento dos objetivos organizacionais. Diante da impossibilidade de satisfazer a todos com políticas uniformes, faz-se necessário o acompanhamento mais individualizado de cada funcionário ou a avaliação periódica do estado geral para diagnóstico das principais questões a serem melhoradas. E, da mesma forma como a organização avalia os funcionários, esses a avaliam em relação às perdas e aos ganhos decorrentes das trocas que realizam com a organização.

A avaliação que o funcionário faz das perdas que ele teria se escolhesse deixar a organização indica o grau de comprometimento calculativo que ele possui em relação à organização. Se essas perdas são consideráveis, o indivíduo pode permanecer com o vínculo, mesmo insatisfeito, e sua insatisfação se manifestará de alguma outra forma em sua vida e na organização. Alguns optam por discutir abertamente o que lhes desagrada, outros esperam por melhoras, outros transferem os problemas para a vida pessoal, podendo até ficar doentes ou desenvolver vícios, e outros ainda podem optar por retaliar o estado de insatisfação, trabalhando de modo insatisfatório para a organização.

Comportamentos como esses, de retaliação, que podem prejudicar a manutenção da efetividade organizacional alcançada ou até causar um decréscimo da mesma, merecem a atenção dos administradores. Atenção redobrada nesse sentido merece a administração pública, que, além de oferecer estabilidade aos trabalhadores, não conta com o empresário ou os acionistas interessados no retorno financeiro para acompanhá-los bem de perto e inibir comportamentos prejudiciais à produtividade deles. Some-se a isso a escassez de recursos públicos e o aumento da demanda pela efetividade dos serviços prestados à população pelo governo, e a necessidade de se debruçar sobre esse campo ficará ressaltada.

Apesar de ser de conhecimento geral que as atitudes retaliatórias têm elevados custos para as organizações, de maneira geral, esse tema tem sido pouco pesquisado no Brasil. São poucos os autores que desenvolvem estudos sobre os desvios de comportamento no local de trabalho. Este estudo visa colaborar para o desenvolvimento dessa relevante temática de pesquisa, por meio da investigação do comprometimento calculativo e da retaliação em uma insti- 
tuição pública, com o intuito de compreender como afetam a eficácia organizacional e prejudicam a manutenção de comportamentos socialmente aceitos.

São objetivos específicos:

(1) analisar a relação entre comprometimento calculativo e percepção de comportamentos retaliatórios com aspectos demográficos;

(2) analisar o comprometimento calculativo dos funcionários em relação à organização estudada à percepção que eles têm referente à emissão de comportamentos de retaliação.

\section{REFERENCIAL TEÓRICO}

\subsection{Comprometimento}

Comprometimento é um tema que desperta o interesse científico da academia e recebe investimentos de pesquisa sem se ater, no entanto, a esse círculo intelectual de geração do conhecimento. As expectativas que se acumulam sobre os efeitos que o comprometimento pode gerar nos indivíduos e, por extensão, nas organizações fornecem um caráter pragmático ao tema, que recebe uma atenção mais ampla e irrestrita em relação aos meios de discussão e uma consequente e constante renovação do incentivo à pesquisa. Entre os efeitos esperados em decorrência de maiores níveis de comprometimento organizacional, estão o aumento da efetividade e da produtividade e a diminuição da rotatividade e do absenteísmo (FIORITO et al., 2007; MEYER; ALLEN; SMITH, 1993). Ainda não é possível afirmar, todavia, qual o efeito do comprometimento das pessoas no desempenho das organizações (MEDEIROS et al., 2003), o que demonstra que a pesquisa sobre comprometimento persiste com lacunas a serem preenchidas e que o esforço de pesquisa que se realiza não é prescindível.

Uma dessas lacunas, o estudo do comprometimento em instituições da administração pública, assume uma importância considerável diante da escassez de recursos públicos e do aumento da demanda pela efetividade dos serviços prestados à população pelo governo. Constatações como as de Borges-Andrade e Pilati (1999), de que a clássica organização burocrática teria uma maior presença de padrões de baixo comprometimento organizacional em relação a outros tipos de organização, agravam a necessidade de se debruçar sobre o tema. Trata-se das disfunções típicas do setor público brasileiro, marcado por um histórico de ineficiência, decorrente de um excessivo aparato burocrático. Flauzino e Borges-Andrade (2008), por outro lado, encontraram moderado comprometimento dos servidores públicos, demonstrando que a administração pública pode estar avançando em relação às suas amarras burocráticas e evidenciando a necessidade de se ampliar o quantitativo de organizações estudadas, para que se tenha um quadro mais fidedigno do comprometimento organizacional do servidor público no contexto das instituições brasileiras.

O termo comprometimento é comumente utilizado quando alguém se refere a relações que se estabelecem entre pessoas, entre uma pessoa e um grupo ou uma pessoa e uma organização. No entanto, à parte o senso comum, não se pode afirmar que haja consenso em relação ao constructo de comprometimento organizacional. Alguns autores (BENKHOFF, 1997; FLAUZINO; BORGES-ANDRADE, 2008; MATHIEU; ZAJAC, 1990) apontam a preponderância do uso da escala Organizational Commitment Questionnaire (OCQ) na pesquisa sobre comprometimento, que tem a característica de medir o comprometimento afetivo, tendo sido caracterizada como uma perspectiva unidimensional do construto. Não obstante, o modelo de 
maior aceitação no meio acadêmico e mais largamente utilizado na pesquisa sobre comprometimento é o multidimensional, de Meyer e Allen (1991). Esse modelo é integrado por diferentes bases, quais sejam as mais citadas: afetiva, instrumental, calculativa ou de continuação e normativa. A base afetiva destaca a natureza emocional que pode unir a pessoa à organização, em função do atendimento de expectativas e necessidades pessoais. A base instrumental, também conhecida como de continuação ou como comprometimento calculativo, enfatiza uma avaliação das perdas e ganhos decorrentes das trocas que o indivíduo faz com a organização. A base normativa refere-se ao sentimento de obrigação do indivíduo para que contribua com a organização.

Contudo, a multidimensionalidade do constructo tem sido criticada (RODRIGUES, 2009; ROWE; BASTOS, 2010; SILVA, 2009). As principais críticas se referem ao antagonismo e à controvérsia entre as três bases, que, talvez por evoluírem de diferentes causas, acabam por resultar, dessa forma, em diferentes consequências. Segundo Moscon, Bastos e Souza (2009, p. 2), o modelo multidimensional de Meyer e Allen (1991) "é cercado de controvérsias e reúne, sob um mesmo rótulo, dimensões do comprometimento que podem ser consideradas quase como antagônicas entre si."

Rodrigues e Bastos (2009, p. 1) corroboram esse posicionamento, principalmente com relação ao comprometimento calculativo, "que apresenta controvérsias em sua estrutura fatorial, comportamento diferenciado dos demais fatores e correlações baixas ou negativas com variáveis desejáveis". Enquanto a base afetiva tem, como conseqüentes, comportamentos desejáveis no trabalho, o comprometimento calculativo não apresenta correlação ou apresenta correlação negativa em relação aos mesmos comportamentos (ROWE; BASTOS; PINHO, 2010; SOLINGER; VAN OLFFEN; ROE, 2008). De acordo com Pinho, Bastos e Rowe (2010, p. 2), "o comportamento de negligência se configura como a única correlação positiva desse vínculo instrumental". Os resultados obtidos por Moscon e Souza (2010), que investigaram a compreensão de gestores acerca do conceito de comprometimento, mostram que estes entendem as características relacionadas à base calculativa como sendo de alguém pouco comprometido. Em suma, o comprometimento calculativo parece ser "uma antítese" do comprometimento (MOSCON; SOUZA, 2010; SCHEIBLE; BASTOS, 2006).

Dessa maneira, esses autores propõem a revisão da multidimensionalidade do conceito e a retirada da base calculativa do mesmo. Outro conceito, de Entricheiramento, proposto por Carson, Carson e Bedeian (1995), mostrou se sobrepor ao comprometimento calculativo (SCHEIBLE; BASTOS; RODRIGUES, 2007). Essa sobreposição foi a razão pela qual Rodrigues (2009, p. 75) propôs o conceito de entricheiramento organizacional, que corresponde à "tendência do indivíduo a permanecer devido a possíveis perdas de investimentos e a custos associados à sua saída e devido à percepção de poucas alternativas fora daquela organização."

De acordo com Carson, Carson e Bedeian (1995), o entrincheiramento não representa necessariamente um problema para as organizações. Para isso, seria preciso se somar à tendência em permanecer na organização, a insatisfação que pode decorrer dessa limitação de possibilidades ou de diversos outros fatores. Segundo Carson e Carson (1997), os indivíduos que se sentem insatisfeitos e estão entrincheirados tenderão a buscar uma solução, seja a sua saída da organização, apesar de todas as dificuldades para tal, a tentativa de confronto em prol de melhoras ou a diminuição de seus investimentos pessoais na organização, começando a ser negligente, a chegar atrasado, faltar ou cometer erros com maior frequência. Contudo, a incipiência das pesquisas acerca desse conceito e seus consequentes no campo organizacional sugere a necessidade de aprofundamento e mais estudos a respeito. Este artigo objetiva contribuir para a discussão sobre a base calculativa do comprometimento e sua relação com compor- 
tamentos de negligência como forma de reação a um estado de insatisfação - em outras palavras, comportamentos de retaliação.

\subsection{Retaliação}

A retaliação poderia ser explicada, em parte, pela teoria proposta por Adams (1965), de acordo com a qual os indivíduos comparam realidade e expectativa e também se comparam uns aos outros. Segundo esse autor, os indivíduos investem em seu trabalho na organização esperando algo em troca e, se não recebem o que esperavam, percebem incongruências na relação de troca estabelecida. Ainda de acordo com essa teoria, eles não ficariam simplesmente insatisfeitos, mas tenderiam a reagir a essa insatisfação de alguma maneira. As respostas para a insatisfação com o trabalho foram representadas por Hirschman (1970) em três categorias: a saída da organização, o abandono, seja pela busca de um novo emprego ou pela demissão; a comunicação, que constitui uma tentativa ativa e construtiva do indivíduo para melhorar as condições; e a lealdade, que seria uma espera passiva, mas construtiva, de que as condições mudem. Farrel (1983) adiciona uma categoria a esse quadro, a negligência, que representa a reação do funcionário que deixa de se empenhar e aumenta a incidência de erros, começa a faltar ou a se atrasar regularmente.

Dentre esses comportamentos, os que afetam o desempenho organizacional são os considerados destrutivos: a saída e a negligência, e, de alguma forma, são os abordados neste artigo. A saída, ou o rompimento do vínculo do indivíduo com a organização, seria uma forma de reagir à incongruência percebida na relação de troca. Mas se o indivíduo, por diversas razões, não pode ou não deseja romper esse vínculo - possui um elevado nível de comprometimento calculativo -, ele pode encontrar na negligência uma forma possível de reação ao estado de insatisfação e de busca pelo reequilíbrio da relação de troca. O comportamento de negligência em resposta a um estado de insatisfação descreve bem o que se denomina retaliação. De acordo com Skarlick e Folger (1997), os primeiros pesquisadores a desenvolver estudos empíricos sobre retaliação, os comportamentos retaliatórios ocorrem com o objetivo de punir a organização ou seus representantes quando as pessoas percebem que estão sendo tratadas injustamente no trabalho e se sentem insatisfeitas com a situação. A retaliação, conforme definição de Skarlick e Folger (1997), é pensada sob a dimensão organizacional, desconsiderando a influência de variáveis individuais e intrapsíquicas na escolha da forma de reação.

Contudo, conforme comprovam Sommers, Terry e Stephen (2002), as diferenças entre os indivíduos podem determinar a tendência a retaliar e/ou agredir. Em meta-análise sobre os preditores de comportamentos agressivos no ambiente de trabalho, Hershcovis et al., (2007) demonstram a importância tanto de características individuais (por exemplo, raiva, afetividade negativa e gênero) quanto situacionais (injustiça, insatisfação, conflito interpessoal, falta de liderança). A moderação exercida por variáveis de personalidade sobre os comportamentos de retaliação foi investigada por Skarlick, Folger e Tesluk (1999), que demonstraram que as pessoas reagem de forma diferente aos tratamentos injustos. Assim, a retaliação poderia ser uma forma de expressão para sentimentos como raiva, ultraje e ressentimento, que surgem em consequência de decisões organizacionais ou ações gerenciais julgadas injustas. Outros estudos confirmam o papel mediador das emoções entre percepção de justiça e comportamentos retaliatórios (ALLRED, 2000; BARCLAY; SKARLICKI; PUGH, 2005; MENDONÇA; MENDES, 2005).

A retaliação pode ocorrer de maneira mais explícita ou bem sutil e pode ser direcionada tanto para chefes quanto para colegas (TOWNSEND; PHILIPS; ELKINS, 2000). Quando o poder da pessoa que se percebe objeto de injustiça é menor que o da fonte que ela percebe como 
geradora da injustiça, a ação de retaliação tende a ser mais indireta, como comportamentos antissociais, de resistência ou de indiferença. (ISMAL; MOHIDEEN; TOGOK, 2009).

Diante desse quadro, pode-se definir retaliação como comportamentos negligentes que sofrem influência de atributos pessoais dos atores organizacionais e que ocorrem de maneira explícita ou sutil em resposta a um estado de insatisfação no trabalho, contra a organização ou pessoas que dela fazem parte.

\section{MÉTODO}

A pesquisa tem perspectiva quantitativa, sendo caracterizada como um estudo transversal simples (VERGARA, 2007). A unidade de análise foi uma organização pública com representações em dez capitais do Brasil, na qual foram recrutados os participantes do estudo e a unidade de observação, o funcionário.

\subsection{Amostra}

A amostragem foi aleatória e estratificada, proporcional por área de atuação (departamentos) dentro da organização. A técnica de amostragem inicial foi probabilística e selecionou aproximadamente $30 \%$ do total de funcionários. Inicialmente, foram considerados os questionários de 575 respondentes. Após a eliminação de casos omissos e o teste de pressupostos para as análises estatísticas, foram mantidos 519 respondentes. Dentre aqueles que indicaram o sexo, $20,6 \%$ eram mulheres e 79,4\% eram homens. A média de idade dos respondentes foi de 45,5 anos $(\mathrm{dp}=10,2)$, e o tempo médio de serviço na organização foi de 17 anos (dp $=12)$. Esses valores para a população são: 18,9\% de mulheres, média de idade de 47,3 anos (dp = 9,9) e média de tempo de serviço de 19,5 anos ( $\mathrm{d} p=11,8)$. O método aleatório e a proximidade desses valores indicam a representatividade da amostra. Todos os respondentes faziam parte do quadro de servidores efetivos da organização, haviam ingressado por meio de concurso público e gozavam de estabilidade.

\subsection{Instrumentos}

Neste estudo, foi utilizado um questionário composto por dois instrumentos: Escala de percepção e julgamento da retaliação organizacional (EPJR) (MENDONÇA; TAMAYO; PAZ, 2004) e a Escala de Comprometimento Organizacional Calculativo (ECOC) (SIQUEIRA, 2008). Os instrumentos foram escolhidos por possuírem parâmetros psicométricos adequados e índices de precisão satisfatórios, além de o EPJR ser o único instrumento, de que se tenha conhecimento, desenvolvido no Brasil até o momento.

De acordo com Siqueira (2008, p. 57), o ECOC pode ser utilizado para avaliação das "crenças de um empregado acerca de perdas ou custos associados ao rompimento das relações de trabalho com uma organização". O instrumento foi desenvolvido e validado a partir de estudo com 192 trabalhadores. Segundo Siqueira (2008), o ECOC é uma medida multidimensional, com quatro componentes: perdas sociais no trabalho, perdas de investimentos feitos na organização, perdas de retribuições organizacionais e perdas profissionais. A escala adotada é de cinco pontos: $1=$ discordo totalmente; $2=$ discordo; $3=$ nem concordo nem discordo; 4 = concordo; e 5 = concordo totalmente. 
O conceito de retaliação adotado para o EPJR é o de "comportamento que ocorre sutilmente em resposta à injustiça no trabalho e é emitido contra a organização ou às pessoas que dela fazem parte" (TAMAYO; MENDONÇA; PAZ, 2008, p. 252). A escala foi construída com base no instrumento desenvolvido por Skarlick e Folger (1997) e adaptada ao contexto brasileiro. O método da observação adotado é indireto, em lugar do autorrelato. Essa opção se justifica como mais adequada à pesquisa de comportamentos socialmente indesejados, como é o caso da retaliação. O EPJR avalia as dimensões perceptivas e avaliativas do comportamento de retaliação. No entanto, apenas a subescala de percepção foi aplicada. O instrumento utiliza uma escala de cinco pontos: variando de 1, correspondente a nunca, a 5, que corresponde a sempre. Segundo Mendonça, Tamayo e Paz (2004), o EPJR em cada uma de suas duas subescalas se estrutura em torno de um único eixo.

\subsection{Procedimento de coleta de dados}

Os convites para a pesquisa foram enviados por correio eletrônico. Neste correio, havia um texto que apresentava a pesquisa e um link externo para o questionário. Após uma semana de coleta, foi realizado um novo convite para aqueles que não haviam respondido até então.

\subsection{Procedimentos de análise de dados}

As 519 respostas obtidas foram tabuladas por meio do Microsoft Excel e posteriormente analisadas estatisticamente por meio do software PASW Statistics 18. Tais análises foram elaboradas de modo que pudessem abranger, de maneira adequada, todos os objetivos propostos para a pesquisa.

Inicialmente, uma análise descritiva preliminar foi conduzida. Em seguida, foram avaliados os valores de skewness e kustosis dos erros padronizados, para verificação da normalidade, que apontaram resultados satisfatórios. Os princípios de linearidade e homocedasticidade dos resíduos também foram verificados graficamente. A estrutura fatorial sugerida pelos autores dos instrumentos foi verificada. Foram realizados testes bivariados de Pearson, para identificar correlações entre as variáveis demográficas, os fatores e alguns dos itens do ECOC.

\section{RESULTADOS E ANÁLISE}

Dentre as perdas ou dificuldades decorrentes de uma hipotética saída da organização elencadas no instrumento, três se destacaram com elevados níveis de concordância entre os respondentes: as dificuldades para ganhar uma remuneração tão boa quanto a que a organização em questão oferece; a perda da estabilidade que a organização oferece; e a avaliação, de maneira geral, de que as perdas superam os ganhos com a saída. Em relação à remuneração, $63 \%$ dos respondentes concordaram (parcial ou totalmente); em relação à estabilidade, $49 \%$ concordaram; e, com relação à comparação entre perdas e ganhos, a percentagem foi de $46 \%$.

Os aspectos que menos retêm os indivíduos nessa organização são relativos à crença de que se estaria jogando fora os esforços despendidos para se aprender as tarefas do cargo atual (65\% de discordância) e para chegar aonde se chegou na organização (60\% de discordância). O tempo que se levaria para se acostumar a outro trabalho também não é um dos aspectos que seriam considerados mais críticos em caso de uma hipotética saída da organização 
(61\% dos respondentes discorda, total ou parcialmente, e apenas $2 \%$ concorda totalmente).

Os comportamentos retaliatórios mais percebidos foram: "Produzir abaixo da capacidade que possui", "Gastar mais tempo no intervalo do que o permitido" e "Fazer corpo mole". Os comportamentos de retaliação menos percebidos foram: "Fazer o serviço malfeito de propósito", "Alterar a forma de fazer as coisas com o intuito de prejudicar a organização" e "Tumultuar o ambiente de trabalho, propositalmente".

Para verificar a estrutura fatorial sugerida pelos autores, alguns critérios foram analisados. A recomendação técnica para análise fatorial é de que a amostra tenha, pelo menos, cinco vezes a quantidade de itens (MALHOTRA, 2007). Nesse caso, considerando os 30 itens que compuseram o questionário, há mais de 17 respondentes por item. Os testes de pressupostos para regressão indicaram a presença de multicolinearidade, verificada por meio dos valores de tolerância e variance inflation factor.

Foram realizados testes para medir o grau de correlação parcial entre as variáveis e para verificar a matriz de correlação. O grau de explicação dos dados encontrado foi excelente: para o ECOC, o valor da estatística KMO foi 0,887 e para a escala de percepção, 0,962. Todos os valores encontrados para essa estatística foram superiores a 0,5, conforme recomendado por Malhotra (2007). Os Barlett's test of sphericity realizados indicaram que nenhuma das matrizes de correlação encontradas é uma matriz identidade. Diante de tais resultados, foi conduzida uma análise fatorial, para testar a distribuição dos itens nos fatores propostos por Mendonça, Tamayo e Paz (2004) e Siqueira (2008). O método dos componentes principais (eigenvalue > $1,0)$ foi utilizado, com rotação ortogonal - Varimax.

\begin{tabular}{|c|c|c|}
\hline Questão & Inicial & Extração \\
\hline $\begin{array}{l}\text { Questão 1: Eu teria dificuldades para ganhar uma remuneração tão boa quanto a que } \\
\text { tenho hoje. }\end{array}$ & 1,000 &, 530 \\
\hline $\begin{array}{l}\text { Questão 2: Eu jogaria fora todos os esforços que fiz para chegar aonde cheguei dentro } \\
\text { desta instituição. }\end{array}$ & 1,000 & ,650 \\
\hline Questão 3: Eu perderia a estabilidade que tenho hoje nesta instituição. & 1,000 & ,688 \\
\hline $\begin{array}{l}\text { Questão 4: Eu teria dificuldade para conseguir outro cargo que me desse o mesmo } \\
\text { prestígio que tenho no meu cargo atual. }\end{array}$ & 1,000 &, 527 \\
\hline $\begin{array}{l}\text { Questão 5: Eu demoraria a encontrar em outra instituição pessoas tão amigas quanto as } \\
\text { que eu tenho hoje entre meus colegas de trabalho dentro desta instituição. }\end{array}$ & 1,000 & ,764 \\
\hline $\begin{array}{l}\text { Questão 6: Eu perderia a liberdade que tenho de realizar meu trabalho dentro desta } \\
\text { instituição. }\end{array}$ & 1,000 &, 677 \\
\hline Questão 7: Eu estaria desperdiçando todo o tempo que já me dediquei a esta instituição. & 1,000 & ,643 \\
\hline Questão 8: Eu deixaria para trás tudo o que já investi nesta instituição. & 1,000 & ,677 \\
\hline Questão 9: Eu estaria prejudicando minha vida profissional. & 1,000 & ,659 \\
\hline $\begin{array}{l}\text { Questão 10: Eu demoraria a conseguir ser tão respeitado em outra instituição quanto sou } \\
\text { hoje dentro desta. }\end{array}$ & 1,000 &, 587 \\
\hline $\begin{array}{l}\text { Questão 11: Eu deixaria de receber vários benefícios que esta instituição oferece aos seus } \\
\text { servidores. }\end{array}$ & 1,000 & ,395 \\
\hline Questão 12: Eu teria mais coisas a perder do que a ganhar com minha saída. & 1,000 & ,620 \\
\hline Questão 13: Eu perderia o prestígio que tenho hoje por ser servidor desta instituição. & 1,000 &, 589 \\
\hline Questão 14: Eu levaria muito tempo para me acostumar a um novo trabalho. & 1,000 &, 566 \\
\hline $\begin{array}{l}\text { Questão 15: Eu estaria jogando fora todo o esforço que fiz para aprender as tarefas do } \\
\text { meu cargo atual. }\end{array}$ & 1,000 & ,634 \\
\hline
\end{tabular}

Fonte: dados da pesquisa.

Quadro 1 - Método de extração: análise de componentes principais 
Da análise do ECOC, emergiram quatro fatores, que conseguem explicar 61,37\% da variância dos dados. Esse valor encontrado foi superior ao relatado por Siqueira (2008), de $56,8 \%$. No entanto, os fatores encontrados tiveram a composição de itens diferente do sugerido por Siqueira (2008), como se depreende do quadro 2.

\begin{tabular}{|c|c|c|c|}
\hline Denominação & Itens & Conteúdo dos itens - perdas ou dificuldades associadas & $\begin{array}{l}\text { Comparação com os } \\
\text { fatores de Siqueira } \\
(2008)\end{array}$ \\
\hline Perdas de & 1 & Remuneração & Itens 1,11 e 12 \\
\hline retribuições & 4 & Prestígio no cargo atual & \\
\hline \multirow[t]{3}{*}{ organizacionais } & 11 & Benefícios & \\
\hline & 12 & Mais coisas a perder do que a ganhar & \\
\hline & 13 & Prestígio por ser funcionário da organização & \\
\hline \multirow[t]{5}{*}{ Perdas profissionais } & 7 & Tempo dedicado à organização & Itens $9,10,13,14 \mathrm{e}$ \\
\hline & 9 & Prejuízo à vida profissional & 15. \\
\hline & 10 & Respeito na organização & \\
\hline & 14 & Tempo para se acostumar a um novo trabalho & \\
\hline & 15 & Esforço para aprender as tarefas do cargo & \\
\hline Perdas de & 2 & Esforços para chegar aonde chegou na organização & Itens 2,7 e 8 \\
\hline investimentos feitos & 3 & Estabilidade & \\
\hline na organização & 8 & Investimento na organização & \\
\hline \multirow[t]{2}{*}{ Perdas sociais } & 5 & Amigos & Itens $3,4,5$ e 6 . \\
\hline & 6 & Liberdade para realizar o trabalho & \\
\hline
\end{tabular}

Fonte: dados da pesquisa e Siqueira (2008, p. 58).

Quadro 2 - Quatro dos componentes do ECOC

Em relação ao fator relativo às perdas de retribuições, a média para a amostra foi de $3,12(\mathrm{dp}=0,78)$, em uma escala de 1 a 5 . Para as perdas profissionais, foi encontrada média de $2,46$ ( $\mathrm{dp}=0,78)$; para as perdas de investimentos, a média foi de 2,75 ( $\mathrm{dp}=0,88$ ); e, para o fator de perdas sociais, a média foi de 2,63 (dp =0,9), conforme apresentado na tabela 1 .

Tabela 1 - Resultados de comprometimento calculativo

\begin{tabular}{lccccc}
\hline Fator & $\bar{x}$ & $\mathrm{~s}$ & $\bar{x} \leq 2,5$ & $2,5<\bar{x} \leq 3,5$ & $\bar{x}>3,5$ \\
\hline Perdas de retribuições organizacionais & 3,12 & 0,78 & $110-21 \%$ & $247-48 \%$ & $162-31 \%$ \\
Perdas profissionais & 2,46 & 0,78 & $300-58 \%$ & $157-30 \%$ & $62-12 \%$ \\
Perdas de investimentos feitos na & 2,75 & 0,88 & $208-40 \%$ & $207-40 \%$ & $104-20 \%$ \\
organização & & & & & \\
\hline Perdas sociais & 2,63 & 0,9 & $288-55 \%$ & $166-32 \%$ & $65-13 \%$ \\
\hline
\end{tabular}

Fonte: dados da pesquisa.

Uma interpretação para os resultados viabilizada pela análise fatorial é a de que a média da avaliação dos itens de cada fator inferior a 2,5 signifique maior tendência à discordância em relação aos aspectos abrangidos por aquele fator; entre 2,5 e 3,5, um posicionamento de dúvida por parte do respondente; e, acima de 3,5, concordância. Os quatro fatores apresentam 
índices de discordância maiores que os de concordância, com exceção do fator referente às retribuições organizacionais, com o qual concordam, parcial ou totalmente, $31 \%$ dos respondentes. O fator que menos representa um motivo para retenção de pessoas na organização é o que se refere às perdas profissionais, com o qual discordaram 58\% dos respondentes, como observado no quadro 2.

Da análise do EPJR, emergiu apenas um fator. A escala de percepção de retaliação explica 59,45\% da variância total (á de Cronbach =0,95). Esse valor encontrado foi próximo ao de Mendonça, Tamayo e Paz (2004): 56,24\%.

Como observado na tabela 2, 46\% dentre os pesquisados têm a percepção de baixa frequência na emissão de comportamentos retaliatórios, de maneira geral (médias inferiores a 2,5 na avaliação de percepção, mais próximos do ponto na escala "1", que significa "nunca"). Nessa mesma linha de análise, apenas 11\% tiveram a média superior a 3,5, indicando que poucos percebem a ocorrência do fenômeno como muito frequente (mais próximo de " 5 ", que significa "sempre"), de maneira geral na organização.

Tabela 2 - Resultados de percepção de retaliação

\begin{tabular}{lccccc}
\hline Fator & $\bar{x}$ & $\mathrm{~s}$ & $\bar{x} \leq 2,5$ & $2,5<\bar{x} \leq 3,5$ & $\bar{x}>3,5$ \\
\hline Percepção de retaliação & 2,60 & 0,77 & $240-46 \%$ & $220-43 \%$ & $59-11 \%$ \\
\hline
\end{tabular}

Fonte: dados da pesquisa.

Os estudos de correlação bivariada objetivaram investigar possíveis relações entre os fatores e cada uma das variáveis demográficas, resumindo, assim, a intensidade de associação entre eles. Como variáveis demográficas, foram analisadas idade, tempo de trabalho na organização e exercício ou não de cargo de chefia. Todas as correlações apontadas foram significativas, a maioria com $p<0,01$; apenas três tiveram $p<0,05$, conforme tabela 3 .

Tabela 3 - Correlações entre fatores e variáveis demográficas

\begin{tabular}{lccc}
\hline Fator & Idade & Tempo de trabalho & $\begin{array}{c}\text { Exercício de cargo de } \\
\text { chefia }\end{array}$ \\
\hline Perdas de retribuições organizacionais & $0,202, p<0,01$ & $0,178, p<0,01$ & - \\
Perdas profissionais & $0,290, p<0,01$ & $0,292, p<0,01$ & - \\
Perdas sociais & $0,103, p=0,019$ & $0,112, p=0,011$ & - \\
\hline Percepção de retaliação & $-0,131, p<0,01$ & $-0,107, p=0,016$ & $0,185, p<0,01$ \\
\hline
\end{tabular}

Fonte: dados da pesquisa.

Os fatores "Perdas de retribuições organizacionais", "Perdas profissionais" e "Perdas sociais" têm correlações positivas com idade e com tempo de trabalho na organização. O fator "Perdas de investimentos feitos na organização" não apresentou correlações. A percepção de comportamentos retaliatórios tem correlação negativa com a idade e com tempo de trabalho na organização e positiva com a situação de exercício ou não de cargo de chefia.

Ademais, foram verificados os itens do ECOC com maiores índices de concordância: "Eu teria dificuldades para ganhar uma remuneração tão boa quanto a que tenho hoje", "Eu perderia a estabilidade que tenho hoje nesta instituição" e "Eu teria mais coisas a perder do que a ganhar com minha saída". Foram encontradas correlações positivas entre os itens relativos à remuneração e à comparação entre perdas e ganhos e idade e tempo de serviço. $\mathrm{O}$ item 
relativo à estabilidade não apresentou correlações com as variáveis sociodemográficas, conforme tabela 4 .

Tabela 4 - Correlações entre itens do ECOC e variáveis demográficas

\begin{tabular}{|lcc|}
\hline \multicolumn{1}{|c|}{ Questão } & Idade & Tempo de serviço \\
\hline $\begin{array}{l}\text { Questão 1: Eu teria dificuldades para ganhar uma remuneração } \\
\text { tão boa quanto a que tenho hoje. }\end{array}$ & $0,149, p<0,01$ & $0,144, p<0,01$ \\
$\begin{array}{l}\text { Questão 12: Eu teria mais coisas a perder do que a ganhar com } \\
\text { minha saída. }\end{array}$ & $0,171, p<0,01$ & $0,136, p<0,01$ \\
\hline
\end{tabular}

Fonte: dados da pesquisa.

\section{DISCUSSÃO DOS RESULTADOS}

A discussão dos resultados se pautará pelos objetivos definidos. O primeiro objetivo específico propunha investigar a relação entre comprometimento calculativo, percepção e julgamento dos comportamentos retaliatórios com algumas variáveis demográficas pessoais e funcionais (idade, tempo de trabalho na organização e exercício ou não de cargo de chefia).

O componente "Perdas de retribuições organizacionais" diz respeito às perdas que o indivíduo teria, que seriam maiores do que os ganhos, e também, mais especificamente, perdas em termos de remuneração, benefícios e prestígio, tanto em relação ao cargo atual que ocupa quanto ao prestígio por ser funcionário da organização. Quanto maior a idade do respondente, maior a percepção desses aspectos como perdas reais, e a correlação do componente com a idade foi positiva e significativa $(0,202)$, assim como em relação ao tempo de trabalho na organização $(0,178)$. O componente "Perdas profissionais" é composto por itens que se referem ao tempo dedicado à organização, ao esforço para aprender as tarefas do cargo, ao respeito que ele já possui, ao tempo que levaria para se acostumar a um novo trabalho e à ideia de que o indivíduo estaria causando um prejuízo à sua vida profissional se saísse da organização. Esse componente apresentou as correlações mais fortes do estudo, tanto com idade $(0,290)$ quanto com tempo de trabalho $(0,292)$. O componente "Perdas sociais", que diz respeito às perdas que o indivíduo poderia sofrer ao deixar a organização relativas às amizades com colegas de trabaIho que cultiva e à liberdade de que dispõe para realizar o seu trabalho, também se correlaciona positivamente com idade e tempo de trabalho. Em síntese, três dos quatro componentes apresentaram correlações positivas e significativas com idade e tempo de serviço na organização. $O$ mesmo tipo de correlação se observa em relação ao item isolado referente à remuneração e ao item isolado relativo à comparação entre perdas e ganhos. Isso significa que, quanto maior a idade e a experiência do indivíduo na organização, mais ele percebe esses itens como perdas capazes de impedi-lo de sair da organização e maior o comprometimento calculativo. Esse resultado faz sentido se analisado sob a perspectiva do conceito de entrincheiramento organizacional, pois, com o passar dos anos, os obstáculos para se sair da organização tendem a aumentar, a trincheira tende a ficar cada vez mais difícil de ser superada.

Com relação à idade do pesquisado e seu tempo de trabalho, foi encontrado ainda que, quanto maior a idade ou a experiência na organização do respondente, a percepção que ele tem em relação aos comportamentos de retaliação é que eles ocorrem com menor frequência. Esses resultados fazem sentido se for considerado que as pessoas vão, com a passagem do tempo, entrincheirando-se cada vez mais, assimilando a cultura do serviço público, assumindo o estereótipo e, com isso, ficando mais tolerantes e menos críticas em relação a comportamentos 
que, na verdade, são sutis e inofensivos se analisados isoladamente. Por outro lado, para aqueles que exercem a função de chefe, a tolerância fica mais de lado, e a percepção para comportamentos retaliatórios se aguça, mostra-se mais frequente, o que pode significar que a pessoa em situação de responder pela produtividade da equipe tende a observar mais e, portanto, registrar como mais frequente a ocorrência de comportamentos de retaliação na organização. O exercício ou não de cargo de chefia não apresentou correlacionamento com nenhum dos outros fatores, exceto este.

O segundo objetivo propunha analisar o comprometimento calculativo dos funcionários em relação à organização estudada e a percepção que os funcionários têm em relação à emissão de comportamentos de retaliação. Três dos quatro componentes do ECOC apresentaram índices de discordância (soma do número de respostas "Discordo" e "Discordo totalmente") maiores que os de concordância (soma do número de respostas "Concordo" e "Concordo totalmente") e tiveram médias baixas: perdas profissionais, 2,46; perdas de investimentos, 2,75; e perdas sociais, 2,63; confirmando a maior tendência à discordância dos respondentes em relação aos itens. A exceção é o componente referente às retribuições organizacionais, com o qual concordam, parcial ou totalmente, $31 \%$ dos respondentes, e discordam $21 \%$. A média para a amostra em relação a esse componente foi um pouco superior do que a média dos demais fatores, porém não se pode afirmar que o valor indique tendência à concordância, pois ele se situa na faixa interpretada como sendo de dúvida: 3,12. De maneira geral, os elevados índices de discordância indicam baixo nível de comprometimento calculativo. Em relação à retaliação, apenas $11 \%$ percebem elevada frequência na emissão de comportamentos retaliatórios, e 46\% percebem baixa frequência. A partir da representatividade da amostra e desses resultados, podese inferir que os comportamentos de retaliação não são muito frequentes na rotina da organização em questão.

Infelizmente, em função de o ECOC adotar o método do autorrelato (as respostas indicam o nível de comprometimento calculativo do respondente) e o EPJR, o da observação indireta (as respostas indicam a percepção que o respondente tem em relação à ocorrência de comportamentos de retaliação na organização), a investigação de correlação entre as variáveis não foi considerada adequada. Porém, essas características dos instrumentos não impedem que os resultados sejam relacionados de maneira agregada. Os resultados demonstram que os funcionários dessa organização possuem um baixo nível de comprometimento calculativo e baixa percepção de retaliação, o que indica uma relação positiva entre os dois constructos. No entanto, sendo a retaliação um comportamento negativo, seria de se esperar que a sua relação com o comprometimento fosse inversa, ou seja, quanto maior o comprometimento, menor seria a percepção de retaliação. Esse resultado corrobora os resultados das outras pesquisas, que demonstram correlações negativas entre a base calculativa do comprometimento em relação a comportamentos desejáveis e correlações positivas em relação a comportamentos indesejáveis, de maneira completamente diferente das outras bases do constructo comprometimento, afetiva e normativa. O resultado corrobora também o estudo de Pinho, Bastos e Rowe (2010), que encontraram a única correlação positiva da base calculativa com comportamentos de negligência. 


\section{CONSIDERAÇÕES FINAIS}

Esta pesquisa buscou colaborar para a discussão sobre a necessidade de revisão da multidimensionalidade do constructo de comprometimento, por meio da corroboração de outros estudos, que sugerem a retirada da base calculativa e o tratamento desse conceito de forma separada, como entrincheiramento organizacional (RODRIGUES, 2009). Recomenda-se a realização de estudos futuros que investiguem as demais bases do comprometimento em relação à percepção de comportamentos de retaliação. Recomenda-se também o acréscimo de outros elementos de investigação, como cultura, relacionamentos entre chefias e subordinados e variáveis psíquicas individuais.

Outro aspecto para o qual esta pesquisa buscou colaborar foi com a discussão dessas questões no contexto da administração pública. Seria de se esperar que os funcionários concursados de um órgão do governo demonstrassem elevado nível de comprometimento calculativo, e, no entanto, os resultados não demonstraram ser absolutamente assim. O mesmo ocorreu com os comportamentos de retaliação, demonstrando que a administração pública pode estar avançando em relação à inibição de comportamentos prejudiciais à produtividade. Persiste, no entanto, a necessidade de se ampliar o quantitativo de organizações estudadas, para que se tenha um quadro mais fidedigno do comprometimento organizacional do servidor público no contexto das instituições brasileiras. Nesse sentido, sugere-se o desenvolvimento de pesquisas como esta em mais organizações públicas e em instituições privadas também, seja para conhecer melhor a ocorrência do fenômeno, seja para tentar identificar as prováveis diferenças existentes em relação à ocorrência da retaliação em organizações públicas e privadas.

Este estudo também buscou colaborar para a compreensão de um tipo de comportamento organizacional que não recebe a merecida atenção, mas que afeta a efetividade organizacional de maneira considerável, seja direta ou indiretamente: a retaliação. A possibilidade de se desenvolver uma linha construtiva de gerenciamento das causas desse tipo de comportamento, com estímulo à busca da disseminação da cultura de meritocracia, do desenvolvimento e amadurecimento das relações, do incremento à prática do feedback, do reconhecimento e da avaliação com mais justiça, estimula o estudo dos antecedentes, sem prescindir de outros estudos, que investiguem a ocorrência e o impacto do fenômeno nas organizações. Uma limitação deste estudo concerne ao fato de que os resultados demonstram a percepção de frequência de comportamentos de retaliação e não a frequência em si ou a intensidade, de maneira que os dados são indiretos e mais imprecisos. Ademais, os comportamentos investigados podem não ser de retaliação, ou seja, podem ocorrer não em resposta a uma injustiça percebida, mas por diversos outros fatores. O desenvolvimento de outra forma de aplicação para mensuração de frequência e intensidade de retaliação seria interessante para o desenvolvimento dessa linha de estudo. 


\section{REFERÊNCIAS BIBLIOGRÁFICAS}

ADAMS, J. S. Inequity in social exchange. In: BERKOWITZ, L. L. (Ed.). Advances in experimental social psychology. New York: Academic Press, 1965. p. 267-299. v. 2

ALLRED, K.G. Anger and retaliation in conflict. In: DEUTSCH, M.; COLEMAN, P. T. (Ed.). The handbook of conflict resolution: theory and practice. San Francisco: Jossey-Bass Publishers, 2000. p. 236-255.

BARCLAY, L. J.; SKARLICKI, D. P.; PUGH, S. D. Exploring the role of emotions in injustice perceptions and retaliation. Journal of Applied Psychology, v. 90, n. 4, p. 629-643, 2005.

BENKHOFF, B. Ignoring commitment is costly: new approaches establish the missing link between commitment and performance. Human Relations, v. 50, n. 6, p. 701-726, 1997.

BORGES-ANDRADE, J. E.; PILATI, R. Comprometimento atitudinal e comportamental: relações com suporte e imagem nas organizações. In: ENCONTRO NACIONAL DOS PROGRAMAS DE PÓS-GRADUAÇÃO E PESQUISA EM ADMINISTRAÇÃO, 23., 1999, Foz do Iguaçu. Anais... Foz do Iguaçu:ANPAD, 1999. 1 CDROM.

CARSON, K.; CARSON, P. Career entrenchment: a quiet march towards occupational death? The Academy of Management Executive, v. 11, n. 1, p. 6275, 1997.

CARSON, K.; CARSON, P.; BEDEIAN, A. Development and construct validation of a career entrenchment measure. Journal of Occupational and Organizational Psychology, v. 68, p. 301-320, 1995.

FARRELL, D. Exit, voice, loyalty and neglect as responses to job dissatisfaction: a multidimensional scaling study. Academy of Management Journal, v. 26, p. 596-607, 1983.
FIORITO, J. et al. Organizational commitment, human resource practices, and organizational characteristics. Journal of Managerial Issues, v. 19, n. 2, p. 186-207, 2007.

FLAUZINO, D. P.; BORGES-ANDRADE, J. E. Comprometimento de servidores públicos e alcance de missões organizacionais. Revista de Administração Pública, v. 42, n. 2, p. 253273, 2008.

HERSHCOVIS, M. S. et al. Predicting workplace aggression: a meta-analysis. Journal of Applied Psychology, v. 92, n. 1, p. 228238, 2007.

HIRSCHMAN, A. Exit, voice, and loyalty: responses to decline in firms, organizations and states. Cambridge: Harvard Press, 1970.

ISMAL, M. N.; MOHIDEEN, M. T. O. K.; TOGOK, S. H. Forgiveness and revenge: empirical study of malaysian business employees. Contemporary Management Research, v. 5, n. 3, p. 227-258, 2009.

MALHOTRA, N. K. Pesquisa de marketing: uma orientação aplicada. São Paulo: Artmed, 2007.

MATHIEU, J. E.; ZAJAC, D. M. A review and meta-analysis of the antecedents, correlates and consequences of organizational commitment. Psychological Bulletin, v. 108, p. 171-194, 1990.

MEDEIROS, C. A. F. et al. Comprometimento organizacional: o estado da arte da pesquisa no Brasil. Revista de Administração Contemporânea, v. 4, n. 7, 2003.

MENDONÇA, H.; MENDES, A. M. Experiências de injustiça, sofrimento e retaliação no contexto de uma organização pública do estado de Goiás. Psicologia em Estudo, Maringá, v. 10, n. 3, p. 489-498, set./dez. 2005.

MENDONÇA, H.; TAMAYO, A.; PAZ, M. G. T. Percepção e julgamento da retaliação organizacional: construção e validação fatorial de um instrumento. Estudos de Psicologia, Natal, v. 9, n. 3, p. 543-551, 2004. 
MEYER, J. P.; ALLEN, N. J. A three-component conceptualization of organizational commitment. Human Resource Management Review, v. 1, p. 61-89, 1991.

MEYER, J. P.; ALLEN, N. J.; SMITH, C. A. Commitment to organizations and occupations: extension and test of a three-component conceptualization. Journal of Applied Psychology, v. 78, n. 4, p. 538-552, 1993.

MOSCON, D. C. B.; SOUZA, J. J. O olhar da liderança sobre o conceito de comprometimento com a organização: uma crítica ao modelo tridimensional. In: ENCONTRO NACIONAL DOS PROGRAMAS DE PÓS-GRADUAÇÃO E PESQUISA EM ADMINISTRAÇÃO, 34., 2010, Rio de Janeiro. Anais... Rio de Janeiro: ANPAD, 2010. 1 CD-ROM.

MOSCON, D. C. B.; BASTOS, A. V. B.; SOU$Z A$, J. J. Perfis de comprometimento e suas articulações com diferentes estratégias cotidianas utilizadas pelos gestores com seus empregados. In: ENCONTRO NACIONAL DOS PROGRAMAS DE PÓS-GRADUAÇÃO E PESQUISA EM ADMINISTRAÇÃO, 33., 2009, São Paulo. Anais... São Paulo: ANPAD, 1999. 1 CDROM.

PINHO, A. P. M.; BASTOS, A. V. B.; ROWE, D. E. O. Comprometimento, entrincheiramento e consentimento organizacionais: o conceito desses vínculos entre gestores que atuam em diferentes organizações. In: ENCONTRO ESTUDOS ORGANIZACIONAIS, 6., 2010, Florianópolis. Anais... Florianópolis: EnEO, 2010. 1 CD-ROM.

RODRIGUES, A. C. A. A questão conceitual do comprometimento e uma possível solução: proposição do construto "entrincheiramento organizacional" e avaliação psicométrica da medida. 2009. 213 f. Dissertação (Mestrado em Psicologia) - Universidade Federal da Bahia, Salvador, 2009.
RODRIGUES, A. C. A.; BASTOS, A. V. B. Problemas conceituais e empíricos na pesquisa sobre comprometimento organizacional: uma análise crítica do modelo tridimensional de J. Meyer e N. Allen. In: ENCONTRO NACIONAL DOS PROGRAMAS DE PÓS-GRADUAÇÃO E PESQUISA EM ADMINISTRAÇÃO, 33., 2009, São Paulo. Anais... São Paulo: ANPAD, 1999. 1 CD-ROM

ROWE, D. E. O.; BASTOS, A. V. B.; PINHO, A. P. M. Comprometimento organizacional e o esforço instrucional de docentes do ensino superior: explorando o impacto das diferentes bases do comprometimento. In: ENCONTRO ESTUDOS ORGANIZACIONAIS, 6., 2010, Florianópolis. Anais... Florianópolis: EnEO, 2010. 1 CD-ROM.

ROWE, D. E. O.; BASTOS, A. V. B. Vínculos com a carreira e produção acadêmica: comparando docentes de IES públicas e privadas. Revista de Administração Contemporânea, v. 14, n. 6, p. 1.011-1.030, 2010.

SCHEIBLE, A. C. F.; BASTOS, A. V. B. Comprometimento com a carreira: explorando o conceito de entrincheiramento. In: ENCONTRO NACIONAL DOS PROGRAMAS DE PÓS-GRADUAÇÃO E PESQUISA EM ADMINISTRAÇÃO, 30., 2006, Salvador. Anais... Salvador: ANPAD, 2006. 1 CD-ROM.

SCHEIBLE, A. C. F.; BASTOS, A. V. B.; RODRIGUES, A. C. A. Comprometimento e entrincheiramento: integrar ou reconstruir? Uma exploração das relações entre estes construtos à luz do desempenho. In: ENCONTRO NACIONAL DOS PROGRAMAS DE PÓSGRADUAÇÃO E PESQUISA EM ADMINISTRAÇÃO, 31., 2007, Rio de Janeiro. Anais... Rio de Janeiro: ANPAD, 2007. 1 CD-ROM.

SILVA, E. E. da C. Consentimento organizacional: uma proposta de medida para o construto. 2009. 168 f. Dissertação (Mestrado em Psicologia) - Instituto de Psicologia, Universidade Federal da Bahia, Salvador, 2009. 
SIQUEIRA, M. M. M. Escala de comprometimento organizacional calculativo. In: SIQUEIRA, M. M. M. (Org.). Medidas de comportamento organizacional: ferramentas de diagnóstico e de gestão. Porto Alegre: Artmed, 2008. p. 57-59, p. 79.

SKARLICKI, D. P.; FOLGER, R. Retaliation in the workplace: the roles of distributive, procedural, and interactional justice. Journal of Applied Psychology, v. 82, n. 3, p. 434443, 1997.

SKARLICKI, D. P.; FOLGER, R.; TESLUK, P. Personality as a moderator in the relationship between fairness and retaliation. Academy of Management Journal, v. 42, p. 100-108, 1999.

SOLINGER, O. N.; VAN OLFFEN, W.; ROE, R. A. Beyond the three-component model of organizational commitment. Journal of Applied Psychology, v. 93, n. 1, p. 70-83, 2008.
SOMMERS, J. A.; TERRY L. S.; STEPHEN, J. V. Developing a measure of individual differences in organizational revenge.

Journal of Business and Psychology, v. 17, n. 2, p. 207-220, 2002.

TAMAYO, A.; MENDONÇA, H.; PAZ, M. G.

T. Atitudes retaliatórias. In: SIQUEIRA, M. M. M. (Org.). Medidas de comportamento organizacional: ferramentas de diagnóstico e gestão. Porto Alegre: Artmed, 2008. p. 249-263.

TOWNSEND, J.; PHILIPS, J. S.; ELKINS, T. J. Employee retaliation: the neglected consequences of poor leader-member exchange relations. Journal of

Occupational Health Psychology, v. 38, n. 4, p. 457-463, 2000.

VERGARA, S. C. Projetos e relatórios de pesquisa em administração. 8. ed. São Paulo: Atlas, 2007. 